Nuntius Antiquus, Belo Horizonte, v. 11, n. 2, p. 33-46, 2015

\title{
O desprezo, a cólera e o riso: o filme The Butcher Boy de Neil Jordan sob uma perspectiva aristotélica
}

\section{The Contempt, the Anger and the Laughter: The film The Butcher Boy under an Aristotelian perspective ${ }^{1}$}

\author{
Carla Milani Damião \\ Faculdade de Filosofia da Universidade Federal de Goiás (FAFIL-UFG) \\ cmdw16@gmail.com
}

Resumo: $\mathrm{O}$ artigo almeja relacionar a paixão da cólera ou raiva, segundo a conceituação de Aristóteles em Retórica das paixões, com o filme The Butcher Boy, dirigido por Neil Jordan, baseado no romance homônimo de Patrick McCabe. Seguindo a caracterização aristotélica da cólera despertada pelo desprezo, despeito e arrogância, consideramos que o que move o desejo de vingança da personagem do filme em questão é do primeiro tipo, sendo o último uma consequência intermediária no desenrolar da trama e assumido, em grande parte, pela ofensa sentida. Trata-se de uma relação não apenas descritiva e psicológica, ou mesmo,

\footnotetext{
${ }^{1}$ Texto apresentado no evento "I Seminário Docere, Delectare et Mouere: Emoções Aristotélicas no Cinema" (Centro de Convenções do Complexo Santuário do Caraça, na região da cidade de Santa Bárbara, Minas Gerais, de 10 a 13 de março de 2015, <www. letras.ufmg.br/doceredelectareetmovere >) organizado por Maria Cecília de Miranda Nogueira Coelho (Departamento de Filosofia da FAFICH-UFMG), como coordenadora geral, e por Helcira Maria Rodrigues de Lima, Sérgio Alcides Pereira do Amaral e Teodoro Rennó Assunção (todos três da FALE/UFMG), e promovido pelo Grupo de Pesquisa "Retórica e Argumentação", do CNPq e UFMG (FAFICH-FALE), pelo "Núcleo de Estudos Antigos e Medievais" (NEAM) do CNPq e UFMG (FALE-FAFICH), com apoio da CAPES, da FAPEMIG, do PPG-FIL da FAFICH/UFMG, do PÓS-LIN e do PÓS-LIT da FALE/UFMG.
} 
ilustrativa da paixão que acomete a personagem, mas de verificar em que medida a narrativa original adaptada para o filme, pode, efetivamente, ser considerada tributária das ideias aristotélicas.

Palavras-chave: paixões; cólera; arrogância; empatia.

Abstract: This article aims to relate the emotion of anger, according to the concept of Aristotle's Rhetoric, with the film The Butcher Boy, by Neil Jordan, based on the eponymous novel by Patrick McCabe. Following Aristotle's characterization of anger arising from contempt, spite and arrogance, we consider that what drives the Butcher Boy's desire for revenge in the film is the first type, the latter being an intermediate result in the unfolding of the plot and assumed, mainly, by offense. It is a relationship not only descriptive and psychological, or even, illustrating the passion that affects the character, but a verification of to what extent the original narrative adapted for the film, can effectively be considered part of Aristotelian ideas.

Keywords: passions; anger; arrogance; empathy.

Recebido em 2 de agosto de 2015

Aprovado em 9 de outubro de 2015

\section{Introdução}

A escolha do filme The Butcher Boy não é uma espécie de ilustração da emoção que caracteriza a cólera em Aristóteles. Trata-se de relacionar um filme, relativamente recente, em contexto histórico e político determinado, à emoção da cólera ou raiva, respeitando algumas diferenças semânticas, de acordo com o enunciado na Retórica das paixões de Aristóteles, em cuja definição lemos: "Seja, então, a cólera

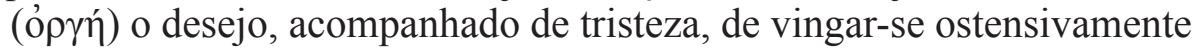
de um manifesto desprezo por algo que diz respeito a determinada pessoa ou a algum dos seus, quando esse desprezo não é merecido". ${ }^{2}$

Uma breve observação sobre a tradução do texto aristotélico revela o que alguns comentadores dizem sobre a variação do uso da palavra thumós e o da palavra ỏ $\rho \gamma \eta ́$ (orgé), traduzida por "cólera"

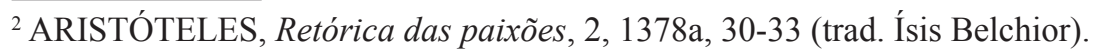


ou raiva, ou ainda impulsividade ou irascibilidade. Em inglês, David Konstan, por exemplo, utiliza "anger" (KONSTAN, 2006, p. 41-76). Há, contudo, quem diga que "anger" é thumós $(\theta v \mu o ́ s)$ e que seu significado evoca a ideia de um "debate espiritual". É comum lembrar que a palavra thumós, em Platão, corresponde a um dos elementos que formam a divisão tripartite da alma, ocupando um lugar intermediário entre noûs (inteligência) e epithumía (apetite). ${ }^{3}$

Há que se notar, entretanto, a variação encontrada na Retórica das Paixões. Giles Pearson ${ }^{4}$ afirma que Aristóteles as emprega como sinônimos. Haveria, portanto, uma alternância do uso das palavras, o que levaria a crer que são utilizadas como sinônimos, embora em passagens de outras obras, nos Tópicos, por exemplo, Aristóteles descreva orgé como uma faculdade ou capacidade de thumós (118; Topics 2.7, 113a36-b1, cf. $4.5126 a 10$ apud PEARSON, 2012). Em outra passagem de Politica (7.7, apud PEARSON, 2012), encontra-se uma ligação entre thumós e phileîn (1327b40-1328a1 apud PEARSON, 2012), sendo o segundo termo um resultado da produção do primeiro. Esta segunda relação torna problemática a interpretação do significado de thumós como desejo de retaliação ou vingança, tal como aparece na Retórica.

A discussão é extensa sobre os termos utilizados orgé e thumós, bem como sobre as variações de escolha de tradução destes. No entanto, notamos apenas que existem divergências de interpretação e que há alternância de palavras. Importa, para essa exposição, seguir a definição da passagem da Retórica sobre a "cólera", levando em consideração algumas adequações e uma interpretação em particular. O que caracteriza a orgé, segundo alguns comentadores, é uma ambiguidade, podendo ser uma espécie de desejo irracional, porém diferenciada dos desejos absolutamente irracionais; por outro lado, é tratada como não sendo apenas uma espécie de desejo irracional.

\section{A emoção da cólera}

Sigo nesta exposição o texto de Aristóteles "Da cólera" (Retórica das paixões, 2, 1378a, 30-33), de acordo com a interpretação de David Konstan (2006, p. 41-76), a fim de buscar a definição do conceito. A

\footnotetext{
${ }^{3}$ PLATÃO, A república, livro II.

${ }^{4}$ PEARSON, 2012 (capítulo 5, em Retórica 2.2, 1378a 31-33).
} 
definição dada, na tradução em português, afirma que "a cólera é (o) desejo, acompanhado de tristeza". Considerando a tradução de Konstan "tristeza" é "pain", dor, sofrimento. A palavra grega é $\lambda u ́ \pi \eta \varsigma$ (lúpes).

$\mathrm{O}$ argumento de Konstan remete ao primeiro parágrafo da passagem em questão, na qual Aristóteles diz que "a toda cólera se

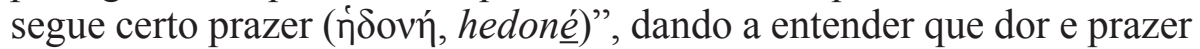
são estados opostos de disposição. Konstan procura mostrar que a cólera é uma paixão (páthos) "acompanhada" por estes dois estados, de dor e de prazer, sendo que estes não se constituem como paixões, mas como sensações (aisthéseis). Toda paixão, portanto, não coincide com a sensação de dor ou prazer, mas é composta por essas, com base no julgamento das pessoas. A paixão da cólera, portanto, não está relacionada ao estímulo ou sensação, mas ao julgamento. Porém, a qual tipo de julgamento? Um julgamento racional? As emoções comportariam uma racionalidade? ${ }^{5}$

Segundo o comentador, não há indicações explícitas de como este julgamento se forma cognitivamente, mas é possível reconhecer que este se baseia em uma dinâmica que envolve crença e decisão. As paixões causam mudanças nas pessoas, diz Aristóteles, e fazem variar seus julgamentos. Em relação à cólera, deve-se admitir quais disposições despertam esta paixão, distinguindo-as do que habitualmente encoleriza. É preciso, neste sentido, existir um motivo.

O que motiva a cólera é o insulto (oligoría), ou desprezo na tradução em português, que causa a dor. O prazer advém do desejo de se vingar contra o insulto. Além disso, tanto a dor como o prazer devem ser perceptíveis. Cólera, neste sentido, não é o mesmo que ódio - uma paixão que Aristóteles vai opor ao amor. O ódio não é perceptível e nem sofrido; é produto da injustiça e da ignorância. Diferentemente do ódio, a cólera não causa dano em geral.

A cólera não se constitui como uma reação instintiva, mas é permeada pela estima social. O insulto (oligoría) se constitui como um valor que repercute nos papéis sociais, com base em intenções e consequências. A palavra oligoría, segundo Konstan, provém de olígos, cujo significado, "pouco" ou "pequeno", remete à diminuição de valor

\footnotetext{
${ }^{5}$ KONSTAN, 2006, p. 43. O autor nota que a afirmação de que as emoções são irracionais só surge no final do século XIX, quando ganham um significado meramente físico, recusando qualquer julgamento a elas relacionado.
} 
de alguém. A definição de Aristóteles é de que ocorre uma "ativação (enérgeia) da crença sobre algo que parece não possuir valor".

Três tipos de insulto ou desprezo são indicados: o desdém (kataphrónesis), a difamação (epereasmós) e o ultraje, ou arrogância abusiva, ou ainda insolência, possíveis traduções de húbris. Novamente o ódio se mostra como um contraponto, pois quem odeia, não desdenha. $\mathrm{O}$ desdém provém do desprezo que se tem por aquilo que se julga desprovido de valor social. A difamação parece provir do desdém, mas serve, efetivamente, como obstáculo, diz Aristóteles, "aos atos de vontade de outrem, não com o fim de que uma coisa seja proveitosa para si mesmo, mas de que não o seja para um outro" (ARISTÓTELES, Retórica, 1378b,10). O ultraje ou injúria tem por função causar "vergonha à vítima". Novamente, não para ganhar proveito com isso, mas a fim de sentir prazer em causar a vergonha. "A causa do prazer para os que ultrajam é pensarem que, ao fazer o mal, aumenta sua superioridade sobre os ultrajados" (ARISTÓTELES, Retórica, 1378b, 30).

A vingança, portanto, é constituída dessa maneira, como essa forma de prazer, premeditada a partir da dor sofrida pelo desdém, pela injúria ou pela arrogância desmedida. A cólera surge, finalmente, como o desejo de restaurar o estado anterior ao insulto. Inscreve-se num contexto social regrado por valores e demanda condições também sociais para que possa ser realizada.

Embora sem o aprofundamento necessário, os pressupostos apresentados sucintamente são importantes e necessários, para relacionálos ao filme em questão.

\section{The Butcher Boy - a música, o livro, a peça e o filme}

The Butcher Boyé o nome de uma música melancólica do folclore inglês, muito conhecida em todos os países de língua inglesa, sobre uma mulher que se apaixona por um açougueiro e se suicida por amor, deixando uma carta de despedida, na qual faz um último pedido. A versão utilizada no filme é da década de 1960. A música está presente no filme e na cena da tentativa de suícidio da mãe, tal e qual descrita na música.

Patrick McCabe escreveu o romance que, inicialmente com outro título e após vinte anos e algumas transformações, foi publicado em 1992 e premiado pelo jornal irlandês The Irish Times como a melhor ficção, foi também finalista do The Man Booker Prize para ficção, uma 
das mais altas premiações para livros em língua inglesa. Em recente edição do livro (McCABE, 2015), seu autor, Patrick McCabe, lembra de uma crítica ao livro que qualificava a narrativa deste como "patafísica". Qualificado também como "comédia macabra", "humor negro", "neosurrealista", o autor prefere iniciar por esta outra qualificação de sua obra. A palavra patafísica filia a narrativa ao non-sense e a um grupo de escritores e artistas próximos a Alfred Jarry, que inventou a narrativa do absurdo, justificando ser uma forma de apresentar o que não era expresso nem pela física, nem pela metafísica. Classificar e explicar o significado de patafísica é uma tarefa como a do tradutor benjaminiano, fadada à desistência, embora muito tenha sido escrito com vigor a respeito, sempre de maneira ambígua e paradoxal (HUGILL, 2012, p. Xv). Importa notar a forte presença do humor negro e do absurdo como elementos constituintes da patafísica. Mas a narrativa de The Butcher Boy tem também inspiração em outras fontes, entre as quais a prosa do conterrâneo James Joyce, do escritor francês Dujardin e de Davis Grubb, autor de The night of the hunter (1953), que resultou também em filme (1955). O ritmo da narrativa de The Butcher Boy advém da quebra de regra de pontuação (quase ausente em longas frases) e da linguagem informal.

O romance foi transformado em peça teatral e recebeu o título Frank pig says hello, e foi encenado pela primeira vez em 1992. A fim de manter a narrativa em primeira pessoa no singular, a personagem foi dividida em duas: ouve-se a voz de Frank, o adulto que narra a história e Piglet (porquinho), a versão infantil da personagem, entra em cena, levando a crer que Frank (o narrador) e Piglet são uma só pessoa. A peça foi composta por 32 cenas e inicia com Frank dizendo Hello, palavra que serve de suporte para ativar a memória e as vozes interiores da personagem.

$O$ filme reúne os meios anteriores, mantendo o ritmo da narrativa do escritor Patrick McCabe, que assina o roteiro com o diretor Neil Jordan. O local determina a história: um vilarejo na área rural da República da Irlanda, cujo modelo seria a própria cidade do escritor. A narrativa, em retrospectiva e na primeira pessoa do singular, recorre também a duas personagens: o adulto (Stephen Rea, ator e protagonista, representa o pai e o adulto) e a criança (Eamonn Owens). Francis Brady narra de forma ritmada, em inglês local, com sotaque e transformações linguísticas. Há uma cronologia dos fatos, dispostos de forma rápida e engraçada. $\mathrm{O}$ engraçado característico do humor cético e cínico, batizado pelos surrealistas como humor negro (dark ou black humor), encontra no 
irlandês Jonathan Swift um precursor, em particular, no livro Modesta proposta (SWIFT, 1729).

As personagens são estereotipadas: ${ }^{6}$ o pai bêbado e músico ou, de acordo com o escritor, o pai não confiável (the unreliable father); a mãe que tenta o suicídio e enlouquece ("the long-suffering mother"); o padre de bochechas vermelhas sempre presente (ubiquitous plum-cheeked clergyman); mulheres alcoviteiras; e a mulher que representa o grande cisma: Ms. Nugent (cuja pronúncia lembra New gents - algo próximo a "os novos senhores"): a personagem é investida pelo confito República da Irlanda-Reino Unido, no início da década de 1960, período conhecido como "neocolonial" ou pelo processo de modernização do país.

Os elementos do imaginário $p o p$ reunidos à percepção infantil são: filmes de faroeste; séries de TV ("O fugitivo"); quadrinhos; extraterrestres e a imagem da explosão da bomba atômica. Como pano de fundo, o macartismo (McCarthyism) e a crise dos mísseis em Cuba. Esses elementos são reunidos à aparição da Virgem Maria - neste caso, aquela que aparece para as crianças: Nossa Senhora de Fátima. A Virgem substitui a mãe, tornando-se real e onipresente em seu relato,e com ela Francis conversa em vários momentos, inclusive no final, sendo um elemento importante de crítica da crença dos moradores do vilarejo e um mote interessante em relação ao personagem.

A história toda é movida pelo insulto ao personagem Francis e sua família pela senhora Nugent. No livro, lemos a passagem:

She said she knew the kind of us long before she went to England and she might have known not to let her son anywhere near the likes of me what else would you expect from a house where the father's never in, lying about the pubs from morning to night, he's no better than a pig ... and the last thing I heard was Nugent going down the lane and calling back Pigs - sure the whole town knows that! ${ }^{7}$ (McCABE, 2014, p. 4)

\footnotetext{
${ }^{6}$ Patrick McCabe diz, sobre a utilização do estereótipo, que ele o utiliza para sugerir que alguns clichês se tornam tais, simplesmente porque são verdadeiros (McCABE, 2015, p. 237).

7 "Ela disse que sabia que tipo de gente éramos muito antes de ir para a Inglaterra, e ela talvez soubesse não permitir que seu filho se aproximasse de alguém como eu, o que se pode esperar de uma casa onde o pai nunca está; encostado em bares da manhã à noite,
} 


\section{$3 \mathrm{O}$ insulto, 0 desprezo e a vingança: as paixões aristotélicas}

De que tipo de insulto se trata? Provavelmente o primeiro (kataphrónesis ou desprezo) e o último (húbris), em diferentes momentos. O segundo (eperreasmós), despeito, parece não estar em questão. O que move o desejo de vingança é do primeiro tipo, sendo o último uma consequência intermediária no desenrolar da trama e assumido, em grande parte, pelo ofendido.

A disposição de raiva na personagem Francis é clara e inicialmente motivada pelo insulto sofrido por ele e sua família. A cólera se dirige à personagem que se constitui no nome como os "novos senhores" (Nugents, New gents), caracterização do "neocolonialismo" inglês. ${ }^{8}$ A cena que se encontra logo no início do filme mostra o tipo de insulto de Nugent na palavra dita repetidamente por ela, com um misto de desprezo e insulto: Pigs!, "Porcos!". Este insulto e o desprezo constituem a linha vermelha que costura toda a trama. Não por acaso, pois se constitui como um insulto à pessoa, à família e à nação. Valho-me aqui de um comentador taiuanês, Yen-Chi Wu (2014), doutor em literatura inglesa, que se deteve na explicação do valor deste insulto aos irlandeses.

Há fontes distintas da associação da Irlanda e dos irlandeses aos porcos. Uma delas (GIBBONS, 2006), afirma que, antes da "descoberta" do Novo Mundo, a situação geográfica da Irlanda a colocava entre o mundo civilizado e o desconhecido primitivo. Mesmo após o descobrimento, a imagem de uma terra primitiva permanecera. Os irlandeses eram vistos não apenas como um povo primitivo, mas insurgentes e supersticiosos, associados à imagem do animal selvagem. No imaginário colonizador britânico, a Irlanda era uma terra selvagem e demonizada a ser dominada, a fim de controlar o que beirava a atitude da insurgência, embriaguez e insanidade. Vistos como uma raça inferior, deveriam ser, "justificadamente", colonizados. Os porcos, pigs, não só correspondem ao outro inferior, mas houve um momento em que a Irlanda foi conhecida como "Ilha dos porcos", por existir uma grande quantidade de porcos na ilha, combinados com uma situação de pobreza. O porco se tornou símbolo da Irlanda e dos irlandeses, transformando-se em uma caricatura da indigência, com teor cômico. Quando os irlandeses, na era

ele não é melhor do que um porco... E a última coisa que vi, foi Nugent descendo a ladeira e gritando para trás: 'Porcos! Certamente todo o vilarejo sabe isso!'” (trad. minha) ${ }^{8}$ Cf. filme The Butcher Boy, de Neil Jordan, 1'-5:31. 
vitoriana, revoltaram-se contra os colonizadores, a figura do porco perdeu o caráter cômico e passou a ser demonizada. O porco selvagem insurgente é, coincidentemente, a figura que se tornou famosa no escrito conservador do irlandês Edmund Burke sobre a revolução francesa. Uma "multidão de suínos" revoltados, era a forma como ele se dirigiu aos revolucionários franceses, os quais, ao invés dese sentirem insultados, adotaram o porco como símbolo de transgressão. Tratou-se aqui de uma inversão retórica, que corresponde a um movimento de reação no filme The Butcher Boy também. Em algumas cenas do filme Francis Brady "veste" o insulto, assume o insulto ao mimetizar o animal, e inicia sua vingança. ${ }^{9}$

Vestir o insulto, entretanto, reagir com húbris, como vemos o valente e arrogante Francis ao dizer às senhoras: "Quem é o porco agora senhoras?" (Who is the pig now ladies?), reflete o prazer da vingança, mas não é suficiente para mostrar o lado mais problemático da trama. $\mathrm{O}$ insulto inicial, que motiva a história, reage com medo ao enfrentamento. A senhora Nugent não ataca mais, é atacada por atitudes ainda brandas que passam a se agravar com outros sofrimentos e perdas de Francis: a morte da mãe, o fim da amizade com seu amigo Joe, a morte do pai.

$\mathrm{Na}$ metáfora do porco se inclui a atitude antropofágica do imperialismo britânico. Jonathan Swift, em Modesta proposta, sugere essa relação quando, diante da pobreza da Irlanda, recomenda que as crianças sejam mortas para alimentar os famintos, e acrescenta: I rather recommend buying the children alive, and dressing them hot from the knife, as we do roasting pigs. ${ }^{10}$

Se o porco, em analogia com a criança, pode representar a situação de um canabalismo imperialista britânico para escritores como Swift em Modesta proposta, para outros escritores irlandeses, como Joyce, por exemplo, a questão é mais complexa. No Retrato do artista quando jovem, a personagem Dedalus diz: Ireland is the old sow that eats her own farrow (JOYCE, apud WU: "A Irlanda é a porca velha que come sua própria ninhada"). Segundo Wu, Joyce sugere que a Irlanda é tão responsável quanto o domínio britânico no que tange o sofrimento de seu povo.

\footnotetext{
${ }^{9}$ Cf. filme The Butcher Boy, de Neil Jordan, 7:43 - 8:47 e 13:18.

${ }^{10}$ SWIFT, 2002, p. 26: "Embora recomende que as crianças sejam compradas vivas e passadas pela faca pouco antes de serem preparadas, como fazemos ao assar os porcos" (trad. Dorothée de Bruchard).
} 
O movimento que seguimos revela como a ofensa move a trama, tendo a história da Irlanda como pano de fundo, reforçando os estereótipos que formam as personagens, ébrias e ensandecidas, por um lado, e temíveis, por outro.

Nos estereótipos, entretanto, e de acordo com o escritor, reside uma verdade. E a verdade, neste caso, seria a famosa indulgência dos irlandeses com a bebida, e a manifestação de doenças mentais que se tornou conhecida na ilha, ao ponto de ver seu epíteto de "Ilha de santos e estudiosos" mudar para "Ilha de santos, estudiosos e esquizofrênicos" [título do livro de Scheper-Hughes (2001)]. Esquizofrenia, alcoolismo e violência tornaram-se um estigma nacional, que nos leva a crer que ser chamado de "porco", além de insultante, foge da simples oposição colonizador-colonizado e passa a agir internamente contra aquele que teme condizer com o insulto.

O romance se passa no período de modernização da Irlanda, durante o governo de Seán Francis Lemass, entre 1959 e 1966. A família Nugent (New gents) corresponde a este processo de modernização. A família Brady corresponde à Irlanda gótica, beberrona, insurgente e insana. Este é o contraste interno que retira o teor panfletário de discurso anticolonizador do filme, e reverte a trama contra si mesma.

O desejo de se tornar um New gent aparece na cena da escola de porcos, quando Francis invade a casa dos Nugents e ensina, fantasiosamente, como um porco deve se comportar. Haveria um recalque na figura do porco que funciona de maneira ambígua: por um lado, há um medo reprimido de corresponder a ela; por outro, na perspectiva moderna-anglicizada, há o medo de conviver com porcos.

$\mathrm{O}$ insulto inicial, apesar da resposta arrogante na sequência, que favorece um certo prazer pela reversão dos papéis, parece ter sido comprovado: a mãe enlouquece e se mata; o pai morre pelo alcoolismo. $\mathrm{O}$ insulto se torna vergonha, mas a situação se agrava e beira a tragédia.

\section{De porco a açougueiro: o assassinato de Nugent}

A narrativa caminha, com internações da personagem em um misto de escola com trabalhos braçais (para a correção do caráter), conduzida por padres. Em vista de um incidente que compromete um dos padres, Francis é enviado de volta para casa, já atormentado por uma carta do amigo Joe que havia aceito um presente dos Nugents. Antes disso, 
ele passa a sofrer alucinações, nas quais surgem padres com cabeças de extraterrestres e a virgem que conversa com ele, e que havia sido levada a sério pelos padres. No retorno à cidade, Francis assume a profissão concreta de açougueiro e comete o crime com o conhecimento adquirido, abatendo e esfolando a vítima como fazia com os porcos no abatedouro. Com o sangue da vítima, escreve nas paredes da casa: porcos! Volta a ser internado por um longo tempo desta vez, saindo da internação ao final do filme, já como adulto, interpretado por Stephen Rea. Na saída, volta a ter a mesma alucinação com a Virgem Maria.

\section{Conclusão: o que pode ou não ser filiado à Retórica aristotélica}

Podemos primeiramente pensar no que não poderia ser considerado aristotélico em relação ao filme. Por exemplo, a cólera não deveria causar dano (KONSTAN, 2006, p. 46). Com isso, o desfecho do filme seria inaceitável sob o ponto de vista da Retórica.

A cólera só pode existir onde possa se realizar. E onde ela não se realiza? Tendo em vista a estratificação social prenunciada por Aristóteles, a cólera não pode pertencer aos não-cidadãos: mulheres, escravos e crianças. Há raras exceções. Devemos perguntar se Francis pode ser visto como uma exceção e por quê.

Uma justificação da criança como motora da cólera seria a de que Francis é ao mesmo tempo vítima e vitimador, amendrontado e ameaçador; ao mesmo tempo, porco e açougueiro. No contexto da família, ele parece portar a capacidade de perceber o insulto e de reagir a ele.

Se a cólera se constitui como o desejo de restaurar o estado anterior ao insulto, o filme mostra, pelo cinismo e ceticismo, a impossibilidade de reconstituição. A velha Irlanda, dos mitos, dos porcos, da bebedeira e da esquizofrenia, deve desaparecer para dar lugar à modernidade. Esse estado reprimido, no entanto, continua latente, de onde brota a cólera pelo insulto. Insulto recentemente, aliás, repetido à Irlanda, mas não somente a ela, quando o jornal britânico Financial Times criou o acrônimo composto em 2006 ao se referir à sigla que reúne os países Portugal, Irlanda, Grécia e Espanha (Spain) como P.I.G.S., no início da crise econômica europeia, fato que gerou a cólera de alguns desses países.

O gênero da "comédia macabra" mostra a emoção da cólera, mas não a causa. Isto é, a narrativa do filme não inspira a cólera, ela mostra a cólera e ri dela. Por um lado, a narrativa não se constitui como um dos 
filmes politicamente panfletários que visam causar a emoção da cólera, ou a indignação da plateia, como vários dos filmes feitos sobre o conflito República da Irlanda-Inglaterra/Reino Unido (Em nome do pai, In the Name of the Father de Jim Sheridan, 1993, entre outros). O que enfraquece, de uma maneira autocrítica, o discurso anti-colonizador-imperialista.

A narrativa mostra a cólera vivida pela personagem infantil que, embora difusa e confusa, é capaz de apresentar melhor discernimento "moral", até um certo ponto, em comparação com seus pais. O cínico e o jocoso retiram o tom trágico das cenas, transformando-as não em comédia, mas em ironia melancólica; causando não a ira, mas o riso. Sabemos, portanto, sobre a cólera que o acomete, compartilhamos desta durante as cenas, sabemos por quem ele se encoleiriza, mas, ao final, o público não é seduzido pela cólera, e sim pelo tom jocoso da narrativa.

Em concordância com isso, vemos que Patrick McCabe tinha a tragédia em mente, mas concebe sua presença na seguinte imagem, igualmente jocosa:

... in the end, I allowed the awful beauty of the bloodsoaked ballad which gives its theme (...) and, without faltering, stammering or second-guessing, allowed the sad hilarity to seep out from its many psychic wounds". (McCABE, 2015, p. 239) (...) the essence of The Butcher Boy is perhaps best expressed by the image of Wile E. Coyote sunk in a big raggy armchair holding back tears as he flips yet another page of Greek tragedy over. ${ }^{11}$ (McCABE, 2015, p. 238)

Nada mais benjaminiano do que essa imagem que recorre a uma espécie de destruição do belo pela destruição da ordem, via ironia dos cartoons e filmes infantis. $\mathrm{O}$ coiote que nunca alcança a ave veloz que passa por ele fazendo bip-bip, encerra a imagem do fracasso, do ceticismo em reconstruir algo pleno de significado. Ao mesmo tempo, desfaz a aparência de uma tentativa de reconstrução deste.

11 “... ao final, eu permiti a beleza terrível da balada [The Butcher Boy - a música], encharcada de sangue, que confere o tema ao livro (...) e, sem vacilar, gaguejar ou adivinhar, deixei escoar a hilaridade triste para fora de suas muitas feridas psíquicas. (...) a essência de The Butcher Boy[o romance] é talvez melhor expressa pela imagem do coiote do Papa Léguas (ou Bip Bip), afundado em uma grande poltrona esfarrapada, segurando as lágrimas enquanto vira mais uma página da tragédia grega" (tradução minha). 
Por fim, embora a apresentação inicial do filme seja feita com imagens de desenhos em quadrinhos, acompanhadas pela balada Mack the knife (1928), composta por Kurt Weill, com letra de Berthold Brecht, não podemos retirar desta abertura uma postura anti-aristotélica ou não-aristotélica, em sentido brechtiano, do diretor do filme. A faca é um importante objeto para o açougueiro e para o garoto-açougueiro, o que nos leva à jocosidade do título da música. Seria, no entanto, uma pista fraca, se julgarmos que a música poderia nos conduzir à crítica brechtiana da "empatia" criada entre público e obra, de forma a causar o efeito catártico. Contrariamente, Brecht propõe o efeito de estranhamento (Verfremdungseffekt), capaz de interromper o processo de identidade e empatia entre público e cena, entre público e personagens. A narrativa composta durante o filme nada apresenta desta técnica de ruptura com a empatia, ao contrário, a narrativa cria empatia entre "heroi" e público, tornando Francis Brady uma personagem cativante, próxima e capaz de suscitar risos com seus atos bárbaros.

\section{Referências}

ARISTÓTELES. Retórica das paixões: 2, 1378a, 30-33. Trad. Ísis Belchior. São Paulo: Martins Fontes, 1999.

DAMIÃO, C. M. Sobre o significado de épico na interpretação benjaminiana de Brecht. In: SELIGMANN-SILVA, M. (org.). Leituras de Walter Benjamin. São Paulo: Annablume/FAPESP, 2007, p. 185-203. GIBBONS, L. Gaelic Gothic: race, colonization, and Irish culture (Research papers in Irish studies). Syracuse: Syracuse University Press, 2006.

HUGILL, Andrew. Pataphysics: a useless guide. Cambridge, Mass./ London: The MIT Press, 2012.

KONSTAN, D. The emotions of the ancient Greeks: studies in Aristotle and classical literature. Toronto/Buffalo/London: University of Toronto Press, 2006.

McCABE, P. The Butcher Boy. London: Picador Classic, 2015.

PEARSON, G. Aristotle on desire. Cambridge: Cambridge University Press, 2012. 
SCHEPER-HUGHES, N. Saints, scholars, and schizophrenics: mental illness in rural Ireland. Berkeley/Los Angeles/London: University of California Press, 2001.

SWIFT, J. A Modest proposal for preventing the children of poor people in Ireland, from being a burden on their parents or country, and for making them beneficial to the public. 1729. Acessado em 28/08/2015<http://www. rotten.com/library/death/cannibalism/a-modest-proposal/>

SWIFT, J. A. Modesta proposta. Trad. Dorothée de Bruchard. São Paulo: Editora Unesp, 2002.

WU, Y.-C. "“Pigs!': Gothic racial stereotype and repressed fear in Patrick McCabe's 'The Butcher Boy'”. Fiction and Drama, Taiwan, vol. 23, n. 2, june 2014 . 